\title{
Os problemas dos Artigos de Revisão
}

\section{Problems with Review Articles}

Muitos periódicos existem que, além de artigos originais, comunicações breves, opiniões etc, publicam também artigos de revisão. Este tipo de artigo é em geral, escrito por autores a convite dos editores, devido a sua reconhecida competência em determinada área do conhecimento, o que significa, via de regra, boa experiência na redação de trabalhos científicos.

Embora seja este o caso no geral, alguns periódicos não exclusivamente editores de revisões, recebem manuscritos que lhe são enviados por autores não convidados. Dentre eles encontram-se, de fato, artigos de boa qualidade quanto a todos os critérios seja de forma, de estilo ou de conteúdo, entretanto outros deixam a desejar (o que, aliás, não é apanágio de Artigos de Revisão). Uma criteriosa primeira análise pelos editores certamente excluirá vários desses, mas os outros seguirão a tramitação normal com o seu fluxo regular até os revisores ad hoc, o que significa, quase sempre, uma série de exigências para melhoria da sua qualidade. Até aí tudo bem porque, tendo alcançado os critérios exigidos, serão aceitos, e caso contrário serão recusados.

Os problemas para uma revista surgem quando a oferta de manuscritos para revisão do tipo narrativa ou de "estado da arte" torna-se muito grande, como tem acontecido, mas, com a maior parte sem atingir um bom nível científico. De fato, o volume trabalho do períodico desde a triagem dos manuscritos pelos editores, é quase hercúleo devido à quantidade de operações que é multiplicada pela quantidade de manuscritos submetidos. Certamente um trabalho de revisão tem a sua especificidade e requer grande conhecimento do tema. Assim, ao ser escrito por pessoas de pouca experiência terá, na revista, um desfecho precário. Ademais as exigências atuais para esse tipo de trabalho são ainda mais rigorosas do que o foram no passado, em virtude da grande aceitação das chamadas Revisões Sistemáticas. Estas, devido aos seus próprios critérios de qualidade, quando bem feitas, preenchem os requisitos para uma boa publicação. Não sabemos a razão desse aumento de oferta, um tanto desproporcional de Artigos de Revisão tipo narrativa, mas, sem esquecer que o periódico pode ter alguma responsabilidade no fenômeno, suspeitamos existir uma pressão externa sobre os autores a fim de escreve-los, sendo grande parte desses autores, jovens pós-graduandos. É possível que necessidades de alguns cursos de pós-graduação, pelo menos no Brasil, com o objetivo de alcançar ou manter conceitos mais altos nos órgãos gestores, sejam grandemente responsáveis por este "efeito de publicar ou perecer".

Em princípio, esta é uma pressão saudável e uma política científica que traz muitos benefícios para o país. Mas compreendemos que a exigência para publicação de artigos em tempo recorde por alunos, muitas vezes inexperientes em redação científica, cria uma situação que pode ser constrangedora para os autores ao terem seus manuscritos recusados.

Desse modo seria muito importante que esta pletora de Artigos de Revisão fosse acompanhada de uma mais alta qualidade no seu conteúdo, forma e justificativas, pois tal condição redundaria na seleção de maior número de bons artigos pelo periódico. Nesse contexto portanto Revisões Sistemáticas serão sempre bem recebidas. No caso da Revista Brasileira de Saúde Materno Infantil o seu número tem até crescido. Ora, desde que este tipo de artigo por ser bastante informativo e apresentar informações com maior confiabilidade, sendo considerado como de excelência, entendemos ser o máximo desejável que os Artigos de Revisão contemplem esse modelo. Sem dúvida isto trará enormes benefícios para a divulgação do conhecimento científico de nível elevado.

Seria pois de bom alvitre que as presentes ponderações fossem levadas em conta pelos autores quando da preparação de Artigos de Revisão a fim de que oferecessem informações as mais relevantes. O mesmo seria recomendável para as Revistas.

Em resumo, para fazer frente ao crescimento geométrico da informação científica, o qual deixa o indivíduo com o sentimento de ser relativamente mais ignorante, boas Revisões Sistemáticas, possibilitando sumarizar o que há de melhor e mais confiável neste oceano de conhecimentos, permitirão aos leitores navegar de modo muito mais seguro sobre ele.

J.E. Cabral-Filho

Editor Executivo

Revista Brasileira de Saúde Materno Infantil 